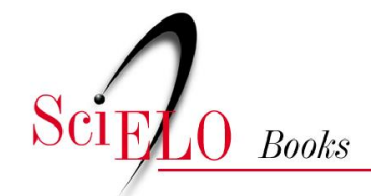

\section{(M) Mackenzie}

\title{
Apresentação
}

\author{
Cristiane Silvestre de Paula
}

\section{SciELO Books / SciELO Livros / SciELO Libros}

PAULA, CS. Apresentação. In: LOWENTHAL, R. Saúde mental na infância: proposta de capacitação para atenção primária [online]. São Paulo: Editora Mackenzie, 2013. Saberes em tese collection, vol. 2, pp. 13-15. ISBN 978-85-8293-727-3. Available from: doi: 10.7476/9788582937273. Also available in ePUB from: http://books.scielo.org/id/db864/epub/lowenthal-9788582937273.epub.

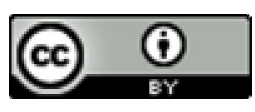

All the contents of this work, except where otherwise noted, is licensed under a Creative Commons Attribution $\underline{4.0 \text { International license. }}$

Todo o conteúdo deste trabalho, exceto quando houver ressalva, é publicado sob a licença Creative Commons Atribição 4.0.

Todo el contenido de esta obra, excepto donde se indique lo contrario, está bajo licencia de la licencia Creative Commons Reconocimento 4.0. 


\section{Apresentação}

A assistência à saúde mental da infância e da adolescência tem complexidades próprias quando comparada ao atendimento de adultos, por isso requer capacitação profissional e serviços específicos. Devido à alta prevalência dos problemas de saúde mental nessa faixa etária e do perfil dessa população, projetos de intervenção e de prevenção devem contar com a articulação de diferentes setores, incluindo os da saúde, educação, assistência social e justiça/direitos. No Brasil, há uma importante defasagem de serviços e recursos humanos especializados no campo da saúde mental da infância e da adolescência. Esse problema é comum à maioria dos países de baixo e médio desenvolvimento. Por isso, segundo a Organização Mundial da Saúde (OMS), aumentar a capacidade de tratamento com base na capacitação profissional continuada é uma das estratégias mais custo-efetivas. Vale ressaltar que o desenvolvimento de programas de capacitação sempre deve vir acompanhado de uma avaliação de sua aplicabilidade e eficácia, para que possa servir de modelo para a saúde pública de uma dada região.

Em 2011, tínhamos credenciado no Brasil apenas um Centro de Atenção Psicossocial da Infância e Adolescência para cada 1,3 milhão de pessoas na região Sudeste e um para cada 5 milhões de pessoas na região Nordeste. No entanto, as unidades básicas de saúde (UBS) podiam ser encontradas em praticamente 
todos os municípios do país, e o Estratégia de Saúde da Família (ESF) já possuía uma cobertura de $53 \%$ da população brasileira. Esses números evidenciam a relevância da Atenção Primária (AP) como local destinado à identificação e ao manejo de problemas de saúde mental na infância e na adolescência. Sabendo ser esse o cenário brasileiro no ano de 2012, faz-se necessário considerar todas as possibilidades que permitam maximizar os recursos existentes.

Assim, reunindo as altas taxas dos problemas com a carência de equipamentos/profissionais especializados, concomitantemente a uma boa disponibilidade de serviços de Atenção Primária, surge o presente projeto para adaptar, implantar e avaliar um modelo de educação interativa sobre saúde mental na infância e na adolescência para capacitação de profissionais de saúde da Atenção Primária.

Este livro é o resultado de um longo caminho de antigas e frutíferas parcerias que foram se acumulando desde 2002, quando frequentei como visiting scholar a Faculdade de Saúde Pública da Universidade John Hopkins nos Estados Unidos. Naquela ocasião, tive a oportunidade de conhecer o professor doutor Lawrence Wissow, pediatra e psiquiatra da infância e da adolescência, e descobrimos o interesse comum de implementar modelos aplicáveis à saúde pública de países de baixo e médio desenvolvimento. $\mathrm{Na}$ época, o Dr. Wissow já havia desenvolvido e testado um modelo desse tipo em alguns países da África e aceitou o desafio de nos ajudar a adaptá-lo para a realidade brasileira.

Posteriormente, nosso grupo de trabalho da Universidade Presbiteriana Mackenzie (UPM), em parceria com dezenas de universidades nacionais e internacionais, sob a liderança do Instituto de Psiquiatria da Universidade de São Paulo (USP), recebeu a aprovação de um dos Institutos Nacionais de Ciências e Tecnologia (INCT) intitulado Instituto Nacional de Psiquiatria do Desenvolvimento (INPD), cujo coordenador é o professor doutor Eurípides Constantino Miguel. O INPD é composto por 16 projetos de capacitação e pesquisa, sendo um deles o "Treinamento em 
saúde mental na infância e adolescência para profissionais do Programa de Saúde da Família” sob minha coordenação. Essa iniciativa permitiu a viabilização da semente que havia sido germinada na Universidade John Hopkins em 2002.

Passados 10 anos, eu tenho a felicidade de fazer a apresentação deste livro que é decorrente de um dos mais relevantes produtos dessa iniciativa: a tese de doutorado de Rosane Lowenthal, a qual tive o prazer de orientar desde o ano de 2009, defendida no Programa de Pós-Graduação em Distúrbios do Desenvolvimento da UPM em junho de 2012. O livro está estruturado em nove capítulos organizados da seguinte forma:

O Capítulo 1 apresenta uma explanação de como estão estruturados o Sistema Único de Saúde (SUS) e o Estratégia de Saúde da Família. O Capítulo 2 aborda o papel do ESF especificamente para a saúde mental, enquanto o Capítulo 3 é dedicado exclusivamente à discussão da saúde mental na infância e na adolescência. O Capítulo 4 afunila os aspectos da saúde mental da infância/ adolescência na área da Atenção Primária.

Os três capítulos seguintes tratam de aspectos teóricos envolvidos em formatos de educação, como as práticas educativas para profissionais que já estão na rede de assistência (Capítulo 5), a proposta inovadora da teleducação interativa (Capítulo 6), assim como os objetos de aprendizagem e as unidades de conhecimento (Capítulo 7).

Os dois capítulos finais abordam o desenvolvimento e a adaptação do modelo de capacitação proposto e sua testagem em um estudo piloto realizado na região oeste da cidade de São Paulo.

Convido-os a desfrutar desse material tão elucidativo, acreditando que servirá como referência para profissionais de diferentes formações e atuantes em diferentes Secretarias, envolvidos com o campo da saúde mental da infância e da adolescência. 